\title{
Ozone-induced changes in murine lung extracellular vesicle number and small RNA
}

\section{content}

Gregory J. Smith, ${ }^{*}{ }^{\dagger}, 1$ Adelaide Tovar, ${ }^{*}{ }^{\ddagger}$ Matt Kanke, ${ }^{\S}$ Praveen Sethupathy, ${ }^{\S}$ and Samir N. P.

Kelada $^{*}, \dagger,+$

*Department of Genetics, ${ }^{\dagger}$ Curriculum in Toxicology \& Environmental Medicine, ${ }^{\ddagger}$ Curriculum in Genetics \& Molecular Biology, University of North Carolina at Chapel Hill, Chapel Hill, NC,

USA; ${ }^{\S}$ Department of Biomedical Sciences, College of Veterinary Medicine, Cornell University, Ithaca, New York.

${ }^{1}$ To whom correspondence should be addressed at Department of Genetics, The University of North Carolina, 120 Mason Farm Road, Chapel Hill, NC 27599, USA.

E-mail: gregory.j.smith@unc.edu.

Keywords: ozone, air pollution, extracellular vesicles, exosomes, micro RNA, lung, inflammation, mouse

Running head: Ozone alters lung extracellular vesicle small RNA expression 


\begin{abstract}
Inhalation exposure to ozone $\left(\mathrm{O}_{3}\right)$ causes adverse respiratory health effects that result from airway inflammation, a complex response mediated by changes to airway cellular transcriptional programs. These programs may be regulated in part by a subset of microRNAs transferred between cells (e.g. epithelial cells and macrophages) via extracellular vesicles (EV miRNA). To explore this, we exposed female C57BL/6J mice to filtered air (FA), 1, or 2 ppm $\mathrm{O}_{3}$ by inhalation and collected bronchoalveolar lavage fluid (BALF) 21 hours later for markers of airway inflammation, EVs, and EV miRNA. Both concentrations of $\mathrm{O}_{3}$ significantly increased markers of inflammation (neutrophils and total protein) and the number of EVs in the BALF. Using high-throughput small RNA sequencing, we identified several differentially expressed (DE) BALF EV miRNAs after 1 ppm (16 DE miRNAs) and 2 ppm (99 DE miRNAs) O 3 versus FA exposure. $\mathrm{O}_{3}$ concentration response patterns in EV miRNA expression were apparent, particularly for the two most highly expressed (miR-2137 and miR-126-3p) and lowly expressed (miR-378-3p and miR-351-5p) miRNAs. Integrative analysis of EV miRNA expression and airway cellular mRNA expression identified EV miR-22-3p as a candidate regulator of transcriptomic responses to $\mathrm{O}_{3}$ in airway macrophages. In contrast, we did not identify candidate miRNA regulators of mRNA expression data from conducting airways (predominantly composed of epithelial cells). In summary, our data show that $\mathrm{O}_{3}$ exposure alters EV release and EV miRNA expression, suggesting that further investigation of EVs may provide insight into their effects on airway macrophage function and other mechanisms of $\mathrm{O}_{3}$-induced respiratory inflammation.
\end{abstract}




\section{Introduction}

Ozone $\left(\mathrm{O}_{3}\right)$ is a highly reactive, oxidant air pollutant associated with significant adverse respiratory health effects including airway inflammation and exacerbation of respiratory diseases such as asthma (1). Observations of the health effects of $\mathrm{O}_{3}$ date to the mid-19th century (47) and yet, knowledge of the underlying mechanisms is still incomplete. Given that ground level $\mathrm{O}_{3}$ concentrations in many regions regularly exceed the current U.S. national standard (0.07 ppm) (53), $\mathrm{O}_{3}$-induced airway inflammation can occur at even lower concentrations (30), and ambient $\mathrm{O}_{3}$ concentrations are expected to rise in the coming decades due to climate change (41), research to identify the mechanisms by which $\mathrm{O}_{3}$ causes respiratory health effects is imperative.

Inhaled $\mathrm{O}_{3}$ reacts rapidly with the airway surface lining liquid to generate reactive oxygen species, lipid peroxides, and other products that induce a complex and dynamic respiratory tract response $(38,42)$. Inflammation occurs up to 48 hours following exposure, initiated in part by the release of cytokines and marked by edema and the influx of neutrophils to the lung (38). Ultimately, the anti-inflammatory and pro-resolving activities of the respiratory tract and innate immune cells restore homeostasis by about 72 hours (29).

Alveolar macrophages and epithelial cells are two airway cell-types with readily apparent functional responses to $\mathrm{O}_{3}(1)$. Alveolar macrophages show reduced phagocytosis (17) and enhanced antigen presentation activity (32). Epithelial cell barrier dysfunction and damage are evidenced by the presence of an intra-alveolar, albumin-rich exudate following $\mathrm{O}_{3}$ exposure (21). Shared functional responses, albeit differing with respect to timing and precise mediators, include the release of pro-inflammatory cytokines (e.g. IL-6 (11), IL-1 family (37), TNF $\alpha$ (13)) and altered production/activity of other proteins (e.g. surfactant (20), metallothionein (24), 
matrix metalloproteinases (55)), and small molecules (e.g. antioxidants (5), eicosanoids (11), specialized pro-resolving lipid mediators (29)).

Underlying the functional cellular responses of airway macrophage and epithelial cells to $\mathrm{O}_{3}$ are alterations in inflammatory, immune, and oxidative stress response gene expression programs. Transcriptomic and proteomic studies have better illuminated the landscape of gene expression responses to $\mathrm{O}_{3}$, revealing the involvement of the protease/anti protease system (28), heat shock proteins (39), and NRF2 (8) and NF-kB family transcription factors (26). Novel $\mathrm{O}_{3}$ responsive genes have also been discovered recently, including oxytocin receptor $(O x t r)$ in conducting airways and hairy enhancer of split 1 (Hes 1) in airway macrophages (51). Although the gene expression landscape of the airway response to $\mathrm{O}_{3}$ is becoming clearer, the precise mechanisms regulating gene expression responses to $\mathrm{O}_{3}$ are unknown.

Extracellular vesicles (EVs) have emerged as an important means of airway intercellular communication and may directly influence gene expression responses of the respiratory tract (18, 36, 44). These nanometer scale, lipid membrane-bound particles carry several classes of cargo including small RNAs such as microRNAs (miRNA) (10). miRNAs regulate gene expression post-transcriptionally by destabilizing or inhibiting the translation of miRNA target-mRNAs, and a single miRNA can regulate hundreds of different mRNAs (4). EV-derived miRNAs (EV miRNAs) are readily detectable in the airway lumen and are taken up by respiratory tract cells including airway macrophages and epithelial cells (18). As such, EVs represent a unique mechanism for the transfer of miRNA, and intercellular miRNA-mediated regulation of airway gene expression.

Inflammatory lung diseases including asthma (35), idiopathic pulmonary fibrosis (40), and chronic obstructive pulmonary disease (COPD)(16) as well as oxidant- or allergen-induced 
lung inflammation $(33,43)$ are associated with altered airway EV miRNA profiles. In addition, there is growing evidence that EV miRNAs directly elicit airway cellular gene expression and phenotypic effects. For example, studies have demonstrated their direct effects on myofibroblast and macrophage differentiation $(25,46)$ and protein secretion by epithelial cells (19). Thus, it is likely that EV miRNA play functional roles in $\mathrm{O}_{3}$-induced inflammation (2); however, the extent to which $\mathrm{O}_{3}$ exposure affects EV miRNA expression is unknown. We hypothesized that $\mathrm{O}_{3}$ exposure dysregulates airway EV miRNAs and that specific dysregulated EV miRNAs correlate with their target mRNA expression changes in airway cells. To investigate this possibility, we conducted high-throughput small RNA sequencing of miRNA isolated from murine airway EVs following filtered air (FA), 1 and 2 ppm $\mathrm{O}_{3}$ exposure and used an integrative bioinformatics approach to identify putative EV miRNA regulators of gene expression in airway macrophages and conducting airways. Here, we provide both an important initial quantification of the murine airway EV miRNA landscape and identify several EV miRNAs as putative regulators of $\mathrm{O}_{3}$ induced gene expression changes.

\section{Materials and Methods}

\section{Animals}

Female C57BL/6J mice at 8 to 10 weeks of age were purchased from the Jackson Laboratory (Bar Harbor, Maine) and used for all experiments. Mice were housed in cages at a maximum density of 5/cage on ALPHA-Dri bedding (Shepard) under standard 12h lighting conditions, with ad libitum access to food (Envigo 2929) and water. After a 1-week acclimation period, mice were randomly assigned to different exposure groups. Whole body inhalation exposures to filtered air (FA), 1 or $2 \mathrm{ppm} \mathrm{O}_{3}$ were conducted as previously described $(48,51)$. 
Environmental conditions for each experiment, including mean $\mathrm{O}_{3}$ concentration (Supplemental Figure 1), temperature, and relative humidity were recorded (Supplemental Table 1). For tissue collection and phenotyping, mice were euthanized with a lethal dose of urethane $(2 \mathrm{~g} / \mathrm{kg}$, i.p.) followed by exsanguination. The sample size for each group is indicated in the figure legends. All experiments were conducted within an AAALAC approved facility and were approved by the Institutional Animal Care and Use Committee (IACUC) at the University of North Carolina at Chapel Hill.

\section{Bronchoalveolar lavage}

Following euthanasia, a $21 \mathrm{~g}$ catheter was inserted in the tracheal lumen 2-cartilage rings posterior to the larynx, towards the lung of the mice. The lung was then gently lavaged twice $(1 \mathrm{x}$ $0.5 \mathrm{~mL}, 1 \times 1 \mathrm{~mL}$ ) with ice-cold PBS containing cOmplete protease inhibitor cocktail (Roche) using a 1-mL syringe. Collected bronchoalveolar lavage fluid (BALF) was centrifuged (400 x g, 10 mins, $4^{\circ} \mathrm{C}$ ) to pellet cells. Red blood cells were lysed with hypertonic saline and the remaining white blood cells were resuspended in Hank's Balanced Salt Solution and counted by hemocytometer and mounted on slides via cytospin. Cytospin slides were stained with Kwik-Diff (Shandon). Two investigators, blinded to exposure group, performed differential cell counts (minimum 300 cells per slide).

\section{EV isolation and characterization}

After the removal of cells (above), a second centrifugation of the BALF was performed $\left(16,000 \times \mathrm{g}, 10 \mathrm{mins}, 4^{\circ} \mathrm{C}\right)$ to pellet cellular debris and larger vesicles (e.g. apoptotic bodies). The concentration and size distribution of particles within the BALF supernatants were then measured prior to EV isolation. Nanoparticle tracking analysis (NTA) was performed on a Nanosight NS500 (Malvern Panalytical) at the UNC Nanomedicines Characterization Core 
Facility. BALF supernatants were diluted 1:100 in $0.02-\mu \mathrm{M}$ filtered PBS prior to loading on the NTA instrument. NTA data were derived from five separate, 40 -second motion captures using Nanosight software v3.2 (Malvern Panalytical).

\section{EV small RNA isolation and expression analysis}

BALF samples were pooled into groups of three to four and total RNA was isolated from pooled samples using an ExoRNeasy Serum/Plasma Midi kit (Qiagen). The ExoRNeasy kit purifies EVs from biofluids using affinity binding columns and total RNA from lysed EVs using an RNA binding column (12). The yield and integrity of small RNA from isolated and lysed EVs were measured using a small RNA chip on an Agilent 2100 Bioanalyzer prior to RNA sequencing, or by Nanodrop 2000 and Qubit high sensitivity RNA assay (Thermofisher) prior to use in RT-qPCR assays. Small RNA sequencing libraries were prepared using a BioO Scientific NEXT Flex-v3 kit. Single end sequencing was performed on the Illumina HiSeq 4000 platform at the UNC High-Throughput Sequencing Facility (University of North Carolina, Chapel Hill, NC, USA). Using miRquant 2.0 (27), small RNA reads were trimmed of adapters, aligned to the Mus musculus domesticus reference genome (assembly NCBI37/mm9), and miRNAs and isomiRs (miRNA sequence variants) were quantified. Small RNA Bioanalyzer results, read length and mapping statistics are presented in the results section and Supplemental Figures 2 and 3.

For RT-qPCR, cDNA synthesis was performed on 10 ng of RNA using a TaqMan advanced miRNA cDNA Synthesis kit (ThermoFisher Scientific). miRNA qPCR reactions were performed in triplicate on a BioRad CFX 384 Touch Real-Time PCR detection system using TaqMan Fast Advanced qPCR Master Mix (ThermoFisher Scientific) according to the manufacturer's instructions. TaqMan Advanced miRNA assays for miR-22-3p 
(mmu481004_mir) and miR-23a-3p (mmu478532_mir) were used for RT-qPCR expression analysis. miR-23a-3p was used for normalization based on its low coefficient of variation in expression across samples measured by small RNA sequencing. miRNA levels are expressed as relative quantitative values (RQVs) and statistical analyses were conducted using $\mathrm{dCq}$ values.

\section{EV miRNA target mRNA prediction}

miRNA target site enrichment analysis was performed on lists of $\mathrm{O}_{3}$-responsive genes identified in our previously published work (51) using the bioinformatics algorithm mirRhub (3). Using, for example, a list of down regulated genes as an input, miRhub determines if any miRNAs are significantly over represented in the 3' UTR TargetScan-predicted miRNA binding sites of the genes as compared to randomly generated gene lists. Identified miRNAs would be expected to be differentially expressed in the opposite direction of the gene list input.

\section{Statistical Analysis}

For analysis presented in Supplemental Figure 2 and Figure 1, raw data were subjected to Box-Cox transformation prior to statistical testing using ANOVA and pairwise t-tests in $\mathrm{R}$ (version 3.6.1). The results of a test were considered significant if the $p$-value was $<0.05$.

\section{Results}

Ozone $\left(\mathrm{O}_{3}\right)$ inhalation causes inflammation and increased extracellular vesicle $(\mathrm{EV})$ sized particles in the lung. We exposed female C57BL6/J mice to filtered air (FA), 1 or 2 ppm $\mathrm{O}_{3}$ for $3 \mathrm{~h}$ and collected bronchoalveolar lavage fluid (BALF) 21h later for isolation of EVs and measurement of lung inflammation and injury. BALF samples from both 1 and 2 ppm $\mathrm{O}_{3}$ exposed mice exhibited characteristic pulmonary inflammatory phenotypes including significant increases in cellularity, driven by macrophages and neutrophils, and injury as measured by increased total protein compared to FA (control) mice (Supplemental Figure 2). As expected, 
both tissue injury and inflammation were most severe in the $2 \mathrm{ppm} \mathrm{O}_{3}$ exposed group, compared to the 1 ppm $\mathrm{O}_{3}$ or FA groups.

We measured the number of particles in BALF across a size range of $\sim 50-1000 \mathrm{~nm}$ by nanoparticle tracking analysis (NTA). We observed a concentration-dependent increase in the total number of BALF particles in the size range of roughly 50-400 nm (Figure 1A). The increase in BALF particle concentration was statistically significant at $2 \mathrm{ppm} \mathrm{O}_{3}$ compared to the 1 ppm $\mathrm{O}_{3}$ and FA groups (Figure 1B). Additionally, we observed modest shifts in the particle size distributions across treatment groups, with both the means and modes of particle size decreasing from FA to $2 \mathrm{ppm} \mathrm{O}_{3}$ (Figures $1 \mathrm{C}$ and D).

Ozone $\left(\mathrm{O}_{3}\right)$ induces miRNA expression changes in lung EVs. To obtain sufficient quantities of small RNA for downstream sequencing, we pooled BALF from three to four mice per treatment group, isolated EV-total RNA from each of the pools, and characterized RNA abundance and size distributions. RNA abundance did not differ between groups (Supplemental Figure 3A), and RNA contents from each pool were predominantly in the size range of 20-30 nucleotides, the size of mature miRNA (Supplemental Figure 3B). To identify $\mathrm{O}_{3}$-responsive EV miRNAs, we performed high-throughput small RNA sequencing (small RNA-seq) on each of the pooled EV RNA samples ( $n=3$ pools/exposure group). Small RNA-seq yielded an average of 44 million reads per sample and, after trimming and exclusion of reads outside 14-40 nucleotides, an average of $78 \%$ of reads were mapped across exposure groups (Supplemental Figure 4A). Read statistics indicate that $1-2 \%$ of reads mapped to miRNA, while the bulk of reads $(\sim 70-90 \%)$ were in the range of 30-35 nucleotides and mapped to tRNA, suggestive of tRNAderived RNA fragments (tDRs) (Supplemental Figures 4B and C). The balance of reads consisted of other small, unannotated RNAs (e.g., yRNAs). Across exposure groups, we 
observed an increase in the percentage of reads mapped to these other small RNAs and a decrease in reads mapped to tRNAs, while the percentage of miRNA was reduced by half in the 2 ppm $\mathrm{O}_{3}$ exposure group from $\sim 2$ to $\sim 1 \%$.

We performed principal components analysis (PCA) on the 50 most variably expressed EV miRNAs, which revealed distinct EV miRNA expression patterns by exposure (Figure 2A). Using fold change of \pm 2 , adjusted $p$ value $<0.05$, and an expression level of $>50$ reads per million miRNAs mapped (RPMMM) as thresholds, we identified 16 significantly differentially expressed EV miRNAs after 1 ppm $\mathrm{O}_{3}$ exposure and 99 significantly differentially expressed EV miRNAs after $2 \mathrm{ppm} \mathrm{O}_{3}$ exposure. Overall, we observed a greater proportion of downregulated versus upregulated EV miRNAs in both the 1 and 2 ppm $\mathrm{O}_{3}$ exposed groups compared to FA (Figures $2 \mathrm{~B}$ and $\mathrm{C}$ ). Hierarchical clustering of the 50 most variably expressed EV miRNAs revealed several different concentration-response patterns of expression including monotonic and non-monotonic relationships (Figure 3A), as we previously observed for mRNAs (51). A threshold effect was observed for the bulk of EV miRNAs, illustrated by the closer correlation of the $\mathrm{FA}$ and $1 \mathrm{ppm} \mathrm{O}_{3}$ groups and greater level of dysregulation in the $2 \mathrm{ppm} \mathrm{O}_{3}$ group (Figure 3A). The most highly upregulated EV miRNA after both 1 and 2 ppm $\mathrm{O}_{3}$ exposure was miR2137 (Figure 3B) as well as several miR-2137 isomiRs generated by alternative processing or nucleotide additions (Supplemental Figure 5). In addition to miR-2137, miR-126-3p was one of the few upregulated miRNAs overall ( $\sim 3.0$ and 4.4 fold, 1 and 2 ppm $\mathrm{O}_{3}$ versus FA) (Figure 3B). The most highly downregulated miRNAs were miR-378-3p ( $\sim 6.8$ and 2.3 fold, 1 and 2 ppm $\mathrm{O}_{3}$ versus FA) and miR-351-5p ( 1.5 and 5.3 fold, 1 and 2 ppm $\mathrm{O}_{3}$ versus FA) (Figure 3B).

\section{Integration of $E V$ miRNA and tissue $m R N A$ data to identify putative regulatory}

networks. Previously, we characterized the transcriptional profiles of airway macrophages and 
conducting airways of mice exposed to $\mathrm{O}_{3}(51)$. We integrated those mRNA expression data with the EV miRNA data presented here as a strategy to identify EV miRNAs that may cause the observed changes in tissue mRNA expression. Specifically, we sought to identify EV miRNAs that could plausibly regulate sets of target mRNAs in recipient airway macrophage or conducting airway tissue. Given the canonical role of miRNAs in decreasing mRNA levels and/or inhibiting mRNA translation (4), we focused our analysis on EV miRNAs whose expression was directionally opposed to the tissue mRNA patterns across the exposure groups (i.e., we paired miRNAs that increased after 1 and 2 ppm $\mathrm{O}_{3}$ with mRNAs that correspondingly decreased, or vice versa), and we stipulated that both miRNA and mRNA must be significantly differentially expressed for the designated contrast.

Our miRhub analysis identified several miRNAs that were predicted to target sets of genes in airway cells (the full set of results are shown in Supplemental Figure 6). miR-22-3p emerged as a particularly interesting candidate regulator of gene expression in airway macrophages (Figure 4) based its target enrichment score, and its relatively high expression level ( $>1,000$ RPMMM). The pattern of $\mathrm{O}_{3}$-induced expression of EV miRs-22-3p is shown alongside one of its predicted target genes, Arhgap26, identified by miRhub (Figure 4B). Of note, in a follow-up experiment in which we exposed mice to $\mathrm{FA}$ or $2 \mathrm{ppm} \mathrm{O}_{3}$, we replicated our finding that EV miR-22-3p was upregulated after 2 ppm O3 exposure (Supplemental Figure 7).

\section{Discussion}

We characterized the extracellular vesicle (EV) profile and EV small RNA content following exposure to filtered air (FA), 1 or $2 \mathrm{ppm} \mathrm{O}_{3}$. Our results demonstrate a clear increase in the number of EVs in the lungs of mice following $\mathrm{O}_{3}$ exposure in parallel with markers of 
inflammation (macrophages, neutrophils, and total protein), indicating that EVs are $\mathrm{O}_{3-}$ responsive and suggesting that they may play a role in regulating $\mathrm{O}_{3}$-induced inflammation.

Collectively, EVs are a heterogeneous population including two known vesicle subtypes, exosomes and microvesicles (44). In general, exosomes are smaller, around 40-100 nm in diameter, while microvesicles can be up to $1,000 \mathrm{~nm}$. Size has been used to specify the subtype of EV being examined in several studies involving airway EVs $(31,34,50)$. In our experiments, $\mathrm{O}_{3}$ exposure caused a decrease in the EV size mode from $\sim 120$ to $100 \mathrm{~nm}$, suggesting that effects of $\mathrm{O}_{3}$ exposure were primarily on exosomes. However, we chose to profile small RNA from the broader EV population for two main reasons: first, the mouse BALF EV small RNA profile has not been examined using high throughput sequencing methods and second, methods for isolating EV subtypes are still in a period of rapid advancement. Previous studies that focus on isolated EVs, even those using 'gold-standard' ultracentrifugation techniques, vary greatly and are difficult to compare directly $(6,12)$. We used a straightforward and commercially available isolation method that excludes non-EV RNA protein aggregates (unlike ultracentrifugation), which has yet to be described in use with mouse BALF samples. Moreover, by isolating a less biased population of EVs, we were able to observe global changes in airway luminal EV miRNA expression. We believe both considerations will help facilitate comparison and reproduction of our work.

Using small RNA-seq, we identified a host of differentially expressed (DE) airway EV miRNAs following $\mathrm{O}_{3}$ exposure. The overall number of DE EV miRNAs and magnitude of change in their expression was concentration-dependent. The majority of DE miRNA were downregulated, which may reflect either a selective decrease in EV loading or a loss of the miRNA's cellular source due to toxicity. miR-2137 was identified as the most highly upregulated 
and expressed EV miRNA across both the 1 ( $\sim 14$ fold $)$ and 2 ppm $\mathrm{O}_{3}(\sim 120$ fold $)$ groups. Recently, differential expression of miR-2137 was observed in bone marrow-derived macrophages after infection with Porphyromonas Gingivalis bacteria (23), and inhibiting miR2137 increased expression of the anti-inflammatory cytokine IL-10 suggesting that miR-2137 may be pro-inflammatory following $\mathrm{O}_{3}$ exposure. We also observed an $\mathrm{O}_{3}$-induced upregulation of EV miR-126-3p, a well-studied pro-inflammatory miRNA (15). miR-126-3p is also upregulated in inflammatory bowel disease (IBD), in which it targets nuclear factor-kappaB inhibitor alpha $(\mathrm{I \kappa B})(14,54)$ and impairs intestinal epithelial barrier function $(7)$. We observed a downregulation of miR-378-3p, whose overexpression has been shown to negatively regulate macrophage proliferation (45). Therefore, the known $\mathrm{O}_{3}$-induced increase in macrophage proliferation is consistent with our results and a potential regulatory effect of EV miR-378-3p (22). miR-351 was also downregulated, and recent evidence suggests that downregulation of miR-351-5p is anti-inflammatory in ischemia/reperfusion injury (57). As such, miR-351-5p may represent a pro-resolving signal after $\mathrm{O}_{3}$ exposure. In general, our data suggest that lung EVs collected 21 hours following $\mathrm{O}_{3}$ exposure contain a mixture of both pro-inflammatory and homeostatic signals.

Our integrative bioinformatics analysis of EV miRNA expression identified miR-22-3p as a putative regulator of airway macrophage gene expression following $\mathrm{O}_{3}$ exposure. A target of miR-22-3p, Arhgap26, exhibited a pattern of expression consistent with miRNA regulation. Interestingly, miR-22-3p is differentially expressed across the continuum of polarized human macrophages (9), suggesting that it may regulate macrophage polarization during $\mathrm{O}_{3}$ exposure. Surprisingly, although miRhub predicted some miRNA regulators for mRNAs in conducting airway tissue, none of these miRNAs were differentially expressed in EVs due to $\mathrm{O}_{3}$ exposure. 
This could be due to timing; for example, an upregulated EV miRNA could have influenced gene expression in conducting airway tissue at a different time point and is no longer or not yet differentially expressed in EVs at 21 hours. This may explain why miR-2137 was not a predicted regulatory hub in either tissue despite its high expression in EVs. Although a number of different cell types (e.g. ciliated epithelium, goblet cells, club cells, etc.) are represented in conducting airway tissue samples, the power to detect miRNA-mRNA target relationships may be reduced by obfuscation or exclusion of critical cell populations. It is also plausible that, on average, EV miRNA communication may have a greater effect on macrophages at this time point than cells of the conducting airways.

In addition to specific miRNA expression, deep sequencing also provided data on the proportion of small RNA species in BALF EVs by type: miRNA, tRNA, or other (e.g. piRNA, yRNA, etc.). We found the majority of BALF EV small RNA reads, from $60-90 \%$ across exposure groups, mapped to tRNAs. A recent study reported a high percentage of tRNA-mapped reads and EV miRNA content on the order of $10-20 \%$ in rodent serum EVs (56). As we are the first to report small RNA-seq data for murine BALF EV samples, the relatively minimal miRNA content (1-2\%) we observed compared to previous serum EV small RNAseq studies was unexpected. Interestingly, the tRNA content of our samples is consistent with tRNA derived RNA fragments (tDRs) based on read length. The biology of tDRs is not well understood; however, evidence suggests they may function similarly to miRNAs by regulating gene expression through RNA interference among other suggested functions (49). The precise annotation and quantification of $\mathrm{O}_{3}$-induced murine EV tDRs is likely to reveal additional biological insights, particularly if specific tDRs are differentially expressed in EVs during airway inflammation. 
EV small RNA content varies by the type of sample, whether collected in vitro (e.g. cell type) or in vivo (e.g. blood, urine, saliva, cell culture supernatant, etc.) (52). Therefore, it is likely that in the lung, EV small RNA content also varies by origin cell type and/or anatomical region. Because we examined a broad population of airway EVs collected from BALF, we could not characterize specific regional or cell-type differences in EV small RNA proportions. Future studies should delineate the regional and cellular sources of EVs using flow-cytometry and fluorescence microscopy-based approaches. These techniques coupled with microdissection would allow for investigation of regional differences in airway EV communication.

Nevertheless, with our global EV small RNA-seq approach, we identified specific miRNAs that may regulate transcriptional responses to $\mathrm{O}_{3}$.

In conclusion, we show that the release of airway EVs and dysregulation of EV miRNA content are features of respiratory tract response to $\mathrm{O} 3$ exposure. In addition to $\mathrm{O} 3$-induced increases in the number of EVs and EV miRNA content, $\mathrm{O} 3$ also induced broad changes in the quantity of other EV small RNA species such as tRNAs. Our preliminary, hypothesis-generating work adds to the growing body of evidence that EV miRNA are both altered by and regulate inflammation in a range of mucosal tissues, including airway responses to $\mathrm{O} 3$ and provide compelling support for a range of mechanistic follow-up studies. In particular, addressing the question of whether changes in EV number and/or content, including miR-22-3p specifically, are responsible for changes in macrophage gene expression and the degree of $\mathrm{O} 3$-induced airway inflammation. 


\section{Acknowledgements}

The authors acknowledge the expert assistance of Kathryn McFadden and Courtney Nesline for assistance with mouse experiments, Dr. Rowan Beck for assistance with miRhub analysis, Dr. Mike Love for consultation on analysis of RNA-seq data, and the UNC HighThroughput Sequencing Facility (library preparation and small RNA-seq).

\section{Grants}

This research was supported by NIH Grants ES024965 and ES007126-35, a UNC Center for Environmental Health and Susceptibility Pilot Project Award (through P30ES010126), a T32 training grant (ES007126-35), and a Leon and Bertha Golberg Postdoctoral Fellowship from the UNC Curriculum in Toxicology and Environmental Medicine.

\section{Disclosures}

None of note.

\section{Author Contributions}

G.J.S. conceived and designed studies with guidance from S.N.P.K and P.S.; G.J.S. and A.T. performed experiments; G.J.S and M.K. analyzed data; G.J.S prepared the manuscript; all authors approved the final version of the manuscript. 


\section{References}

1. Al-Hegelan M, Tighe RM, Castillo C, Hollingsworth JW. Ambient ozone and pulmonary innate immunity. Immunol Res 49: 173-191, 2011.

2. $\quad$ Andres J, Smith LC, Murray A, Jin Y, Businaro R, Laskin JD, Laskin DL. Role of extracellular vesicles in cell-cell communication and inflammation following exposure to pulmonary toxicants. Cytokine Growth Factor Rev. 51 Elsevier Ltd: 12-18, 2020.

3. Baran-Gale J, Fannin EE, Kurtz CL, Sethupathy P. Beta Cell 5'-Shifted isomiRs Are Candidate Regulatory Hubs in Type 2 Diabetes. PLoS One 8: e73240, 2013.

4. Bartel DP. Metazoan MicroRNAs. Cell 173 Cell Press: 20-51, 2018.

5. Behndig AF, Blomberg A, Helleday R, Duggan ST, Kelly FJ, Mudway IS. Antioxidant responses to acute ozone challenge in the healthy human airway. Inhal Toxicol 21: 93342, 2009.

6. Carnino JM, Lee H, Jin Y. Isolation and characterization of extracellular vesicles from Broncho-alveolar lavage fluid: a review and comparison of different methods. Respir Res 20: $240,2019$.

7. Chen T, Xue H, Lin R, Huang Z. MiR-126 impairs the intestinal barrier function via inhibiting S1PR2 mediated activation of PI3K/AKT signaling pathway. Biochem Biophys Res Commun 494: 427-432, 2017.

8. Cho H-Y, Gladwell W, Yamamoto M, Kleeberger SR. Exacerbated Airway Toxicity of Environmental Oxidant Ozone in Mice Deficient in Nrf2. Oxid Med Cell Longev 2013, 2013.

9. Cobos Jiménez V, Bradley EJ, Willemsen AM, van Kampen AHC, Baas F, Kootstra NA. Next-generation sequencing of microRNAs uncovers expression signatures in 
polarized macrophages. Physiol Genomics 46: 91-103, 2014.

10. Crescitelli R, Lässer C, Szabó TG, Kittel A, Eldh M, Dianzani I, Buzás EI, Lötvall J.

Distinct RNA profiles in subpopulations of extracellular vesicles: apoptotic bodies, microvesicles and exosomes. J Extracell Vesicles 2: 20677, 2013.

11. Devlin RB, McDonnell WF, Mann R, Becker S, House DE, Schreinemachers D, Koren HS. Exposure of humans to ambient levels of ozone for 6.6 hours causes cellular and biochemical changes in the lung. Am J Respir Cell Mol Biol 4: 72-81, 1991.

12. Enderle D, Spiel A, Coticchia CM, Berghoff E, Mueller R, Schlumpberger M, Sprenger-Haussels M, Shaffer JM, Lader E, Skog J, Noerholm M. Characterization of RNA from exosomes and other extracellular vesicles isolated by a novel spin columnbased method. PLoS One 10, 2015.

13. Fakhrzadeh L, Laskin JD, Laskin DL. Regulation of caveolin-1 expression, nitric oxide production and tissue injury by tumor necrosis factor- $\alpha$ following ozone inhalation. 227: 380-389, 2008.

14. Feng X, Wang H, Ye S, Guan J, Tan W, Cheng S, Wei G, Wu W, Wu F, Zhou Y. UpRegulation of microRNA-126 May Contribute to Pathogenesis of Ulcerative Colitis via Regulating NF-kappaB Inhibitor I $\mathrm{B} \alpha$. PLoS One 7: e52782, 2012.

15. Fogel O, Bugge Tinggaard A, Fagny M, Sigrist N, Roche E, Leclere L, Deleuze JF, Batteux F, Dougados M, Miceli-Richard C, Tost J. Deregulation of microRNA expression in monocytes and CD4+ T lymphocytes from patients with axial spondyloarthritis. Arthritis Res Ther 21: 1-14, 2019.

16. Fujita Y, Araya J, Ito S, Kobayashi K, Kosaka N, Yoshioka Y, Kadota T, Hara H, Kuwano K, Ochiya T. Suppression of autophagy by extracellular vesicles promotes 
myofibroblast differentiation in COPD pathogenesis. J Extracell Vesicles 4: 28388, 2015.

17. Gilmour MI, Hmieleski RR, Stafford EA, Jakab GJ. Suppression and recovery of the alveolar macrophage phagocytic system during continuous exposure to $0.5 \mathrm{ppm}$ ozone. Exp Lung Res 17: 547-558, 1991.

18. Guiot J, Struman I, Louis E, Louis R, Malaise M, Njock M-S. Exosomal miRNAs in Lung Diseases: From Biologic Function to Therapeutic Targets. J Clin Med 8: 1345, 2019.

19. Gupta R, Radicioni G, Abdelwahab S, Dang H, Carpenter J, Chua M, Mieczkowski PA, Sheridan JT, Randell SH, Kesimer M. Intercellular communication between airway epithelial cells is mediated by exosome-like vesicles. Am J Respir Cell Mol Biol 60: 209$220,2019$.

20. Haque R, Umstead TM, Ponnuru P, Guo X, Hawgood S, Phelps DS, Floros J. Role of surfactant protein-A (SP-A) in lung injury in response to acute ozone exposure of SP-A deficient mice. Toxicol Appl Pharmacol 220: 72-82, 2007.

21. Hollingsworth JW, Kleeberger SR, Foster WM. Ozone and pulmonary innate immunity. Proc Am Thorac Soc 4: 240-246, 2007.

22. Hotchkiss JA, Harkema JR, Kirkpatrick DT, Henderson RF. Response of rat alveolar macrophages to ozone: Quantitative assessment of population size, morphology, and proliferation following acute exposure. Exp Lung Res 15: 1-16, 1989.

23. Huck O, Al-Hashemi J, Poidevin L, Poch O, Davideau JL, Tenenbaum H, Amare S. Identification and characterization of microRNA differentially expressed in macrophages exposed to Porphyromonas gingivalis infection. Infect Immun 85, 2017.

24. Inoue K ichiro, Takano H, Kaewamatawong T, Shimada A, Suzuki J, Yanagisawa R, Tasaka S, Ishizaka A, Satoh M. Role of metallothionein in lung inflammation induced 
by ozone exposure in mice. Free Radic Biol Med 45: 1714-1722, 2008.

25. Ismail N, Wang Y, Dakhlallah D, Moldovan L, Agarwal K, Batte K, Shah P, Wisler J, Eubank TD, Tridandapani S, Paulaitis ME, Piper MG, Marsh CB. Macrophage microvesicles induce macrophage differentiation and miR-223 transfer. Blood 121: 984$995,2013$.

26. Jaspers I, Flescher E, Chen LC. Ozone-induced IL-8 expression and transcription factor binding in respiratory epithelial cells. Am J Physiol - Lung Cell Mol Physiol 272, 1997.

27. Kanke M, Baran-Gale J, Villanueva J, Sethupathy P. miRquant 2.0: an Expanded Tool for Accurate Annotation and Quantification of MicroRNAs and their isomiRs from Small RNA-Sequencing Data. J Integr Bioinform 13: 307, 2016.

28. Kesic MJ, Meyer M, Bauer R, Jaspers I. Exposure to ozone modulates human airway protease/antiprotease balance contributing to increased influenza a infection. PLoS One 7: $1-12,2012$.

29. Kilburg-Basnyat B, Reece SW, Crouch MJ, Luo B, Boone AD, Yaeger M, Hodge M, Psaltis C, Hannan JL, Manke J, Armstrong ML, Reisdorph N, Tighe RM, Shaikh SR, Gowdy KM. Specialized Pro-Resolving Lipid Mediators Regulate Ozone-Induced Pulmonary and Systemic Inflammation. Toxicol Sci : 20-22, 2018.

30. Kim CS, Alexis NE, Rappold AG, Kehrl H, Hazucha MJ, Lay JC, Schmitt MT, Case M, Devlin RB, Peden DB, Diaz-Sanchez D. Lung function and inflammatory responses in healthy young adults exposed to 0.06 ppm ozone for 6.6 hours. Am J Respir Crit Care Med 183: 1215-1221, 2011.

31. Kulshreshtha A, Ahmad T, Agrawal A, Ghosh B. Proinflammatory role of epithelial cell-derived exosomes in allergic airway inflammation. J Allergy Clin Immunol 131: 
1194-1203.e14, 2013.

32. Lay JC, Alexis NE, Kleeberger SR, Roubey RAS, Harris BD, Bromberg PA,

Hazucha MJ, Devlin RB, Peden DB. Ozone enhances markers of innate immunity and antigen presentation on airway monocytes in healthy individuals. J. Allergy Clin.

Immunol. 120 Elsevier: 719-722, 2007.

33. Lee H, Li C, Zhang Y, Zhang D, Otterbein LE, Jin Y. Caveolin-1 selectively regulates microRNA sorting into microvesicles after noxious stimuli. J Exp Med 216: 2202-2220, 2019.

34. Lee H, Zhang D, Zhu Z, Dela Cruz CS, Jin Y. Epithelial cell-derived microvesicles activate macrophages and promote inflammation via microvesicle-containing microRNAs. Sci Rep 6: 35250, 2016.

35. Levänen B, Bhakta NR, Torregrosa Paredes P, Barbeau R, Hiltbrunner S, Pollack JL, Sköld CM, Svartengren M, Grunewald J, Gabrielsson S, Eklund A, Larsson BM, Woodruff PG, Erle DJ, Wheelock ÅM. Altered microRNA profiles in bronchoalveolar lavage fluid exosomes in asthmatic patients. J Allergy Clin Immunol 131: 18-23, 2013.

36. McVey MJ, Maishan M, Blokland KEC, Bartlett N, Kuebler WM. Extracellular vesicles in lung health, disease, and therapy. Am. J. Physiol. - Lung Cell. Mol. Physiol. 316 American Physiological Society: L977-L989, 2019.

37. Michaudel C, Couturier-Maillard A, Chenuet P, Maillet I, Mura C, Couillin I, Gombault A, Quesniaux VF, Huaux F, Ryffel B. Inflammasome, IL-1 and inflammation in ozone-induced lung injury. Am. J. Clin. Exp. Immunol. 5: 33-40, 2016.

38. Mudway IS, Kelly FJ. Ozone and the lung: A sensitive issue. 2000.

39. Nadadur SS, Costa DL, Slade R, Silbjoris R, Hatch GE. Acute ozone-induced 
differential gene expresssion profiles in rat lung. Environ Health Perspect 113: 1717$1722,2005$.

40. Njock MS, Guiot J, Henket MA, Nivelles O, Thiry M, Dequiedt F, Corhay JL, Louis

RE, Struman I. Sputum exosomes: Promising biomarkers for idiopathic pulmonary fibrosis. Thorax 74: 309, 2018.

41. Pfister GG, Walters S, Lamarque J-F, Fast J, Barth MC, Wong J, Done J, Holland G, Bruyère CL. Projections of future summertime ozone over the U.S. J Geophys Res Atmos 119: 5559-5582, 2014.

42. Pryor WA, Squadrito GL, Friedman M. The cascade mechanism to explain ozone toxicity: The role of lipid ozonation products. Free Radic Biol Med 19: 935-941, 1995.

43. Pua HH, Happ HC, Gray CJ, Mar DJ, Chiou NT, Hesse LE, Ansel KM. Increased Hematopoietic Extracellular RNAs and Vesicles in the Lung during Allergic Airway Responses. Cell Rep. (2019). doi: 10.1016/j.celrep.2019.01.002.

44. Raposo G, Stoorvogel W. Extracellular vesicles: Exosomes, microvesicles, and friends. $J$ Cell Biol 200: 373-383, 2013.

45. Rückerl D, Jenkins SJ, Laqtom NN, Gallagher IJ, Sutherland TE, Duncan S, Buck AH, Allen JE. Induction of IL-4R $\alpha$-dependent microRNAs identifies PI3K/Akt signaling as essential for IL-4-driven murine macrophage proliferation in vivo. Blood 120: 2307$2316,2012$.

46. Saha B, Momen-Heravi F, Kodys K, Szabo G. MicroRNA Cargo of Extracellular Vesicles from Alcohol-exposed Monocytes Signals Naive Monocytes to Differentiate into M2 Macrophages. J Biol Chem 291: 149-59, 2016.

47. Schönbein CF. On Some Secondary Physiological Effects Produced by Atmospheric 
Electricity. J R Soc Med MCT-34: 205-220, 1851.

48. Smith GJ, Walsh L, Higuchi M, Kelada SNP. Development of a large-scale computercontrolled ozone inhalation exposure system for rodents. Inhal Toxicol 0: 1-12, 2019.

49. Soares AR, Santos M. Discovery and function of transfer RNA-derived fragments and their role in disease. Wiley Interdiscip Rev RNA 8: 1-13, 2017.

50. Soni S, Wilson MR, O’Dea KP, Yoshida M, Katbeh U, Woods SJ, Takata M.

Alveolar macrophage-derived microvesicles mediate acute lung injury. Thorax 71: 1020$1029,2016$.

51. Tovar A, Smith GJ, Thomas JM, Crouse WL, Harkema JR, Kelada SNP.

Transcriptional Profiling of the Murine Airway Response to Acute Ozone Exposure.

Toxicol. Sci. (2020). doi: 10.1093/toxsci/kfz219.

52. Turchinovich A, Drapkina O, Tonevitsky A. Transcriptome of extracellular vesicles:

State-of-the-art. Front Immunol 10, 2019.

53. U.S. Environmental Protection Agency. Nonattainment Areas for Criteria Pollutants

[Online]. Green B.: 2020. https://www.epa.gov/green-book.

54. Wu F, Zikusoka M, Trindade A, Dassopoulos T, Harris ML, Bayless TM, Brant SR,

Chakravarti S, Kwon JH. MicroRNAs Are Differentially Expressed in Ulcerative Colitis and Alter Expression of Macrophage Inflammatory Peptide-2 $\alpha$. Gastroenterology 135, 2008.

55. Yoon H-K, Cho H-Y, Kleeberger SR. Protective Role of Matrix Metalloproteinase-9 in Ozone-Induced Airway Inflammation. Environ Health Perspect 115: 1557-1563, 2007.

56. Zhao F, Cheng L, Shao Q, Chen Z, Lv X, Li J, He L, Sun Y, Ji Q, Lu P, Ji Y, Ji J. Characterization of serum small extracellular vesicles and their small RNA contents 
across humans, rats, and mice. Sci Rep 10: 1-16, 2020.

\section{Zheng L, Han X, Hu Y, Zhao X, Yin L, Xu L, Qi Y, Xu Y, Liu K, Peng J. Dioscin}

ameliorates intestinal ischemia/reperfusion injury via adjusting miR-351-5p/MAPK13-

mediated inflammation and apoptosis. Pharmacol Res 139: 431-439, 2019. 


\section{Figure Legends}

Figure 1. $\mathrm{O}_{3}$ exposure increases in extracellular vesicle-sized particles in the lung. Nine to tenweek-old female C57BL/6J mice were exposed to filtered air $(\mathrm{FA} ; \mathrm{n}=12), 1(\mathrm{n}=9)$ or $2(\mathrm{n}=9)$ ppm $\mathrm{O}_{3}$ for $3 \mathrm{~h}$ and bronchoalveolar lavage fluid was collected at $21 \mathrm{~h}$ for isolation and analysis of extracellular vesicles. (A) Size distribution, (B) total concentration, (C) size mean, and (D) size mode of particles in BALF samples were measured by nanoparticle tracking analysis. Results are depicted in (A) as the mean particle-size distribution. In (B-D) box-and-whisker plots depict the minimum, first quartile, median, third quartile, and maximum of the data with all points overlaid. a: $p<0.05$ compared to FA group, b: $p<0.05$ compared to $1 \mathrm{ppm}$ group.

Figure 2. $\mathrm{O}_{3}$ exposure alters airway extracellular vesicle miRNA expression. (A) Principal components analysis showing separation of pooled airway EV samples by exposure group. (B and C) Volcano plots showing differentially expressed (DE) miRNAs in 1 ppm O 3 versus FA (16 DE miRNAs) and 2 ppm $\mathrm{O}_{3}$ versus FA (99 DE miRNAs), respectively (horizontal line: $\mathrm{p}=0.05$, vertical lines: fold change of \pm 2 ). Three pooled and isolated EV-RNA samples were analyzed per exposure group.

Figure 3. Specific $\mathrm{O}_{3}$-induced alterations of the EV-miRNA landscape. (A) Unsupervised hierarchical clustering analysis of the top 50 most variable EV-miRNAs. Data are presented as mean-centered, $\log _{2}$-transformed reads per million miRNAs mapped (RPMMM) for each miRNA. (B) Expression of selected, $\mathrm{O}_{3}$-responsive EV-miRNAs. Box-and-whisker plots depict RPMMM summarized by the minimum, first quartile, median, third quartile, and maximum with all points overlaid. $n=3$ pooled samples per group. 


\section{Figure 4. Identification of candidate $E V$-miRNA regulators of $O_{3}$-induced transcriptional}

responses. (A) Representative plot showing output of the miRhub algorithm used to identify miR-22-3p as a potential candidate regulatory hub from a list of downregulated genes $\left(2 \mathrm{ppm} \mathrm{O}_{3}\right.$ versus FA) genes in airway macrophages following $\mathrm{O}_{3}$ exposure. All lists included genes with a fold change of \pm 2 , and $p$ value $<0.05$. Data points are plotted as $-\log _{10}(p$-value $)$ generated from miRhub by miRNA family, and are highlighted if a member of the miRNA family was found to be differentially expressed in airway EVs. (B) Plot depicting RPMMM for EV miR-22-3p alongside predicted airway macrophage mRNA target expression (normalized counts from Deseq2). $\mathrm{n}=3$ or 4 (mRNA data) pooled samples per group. 
A

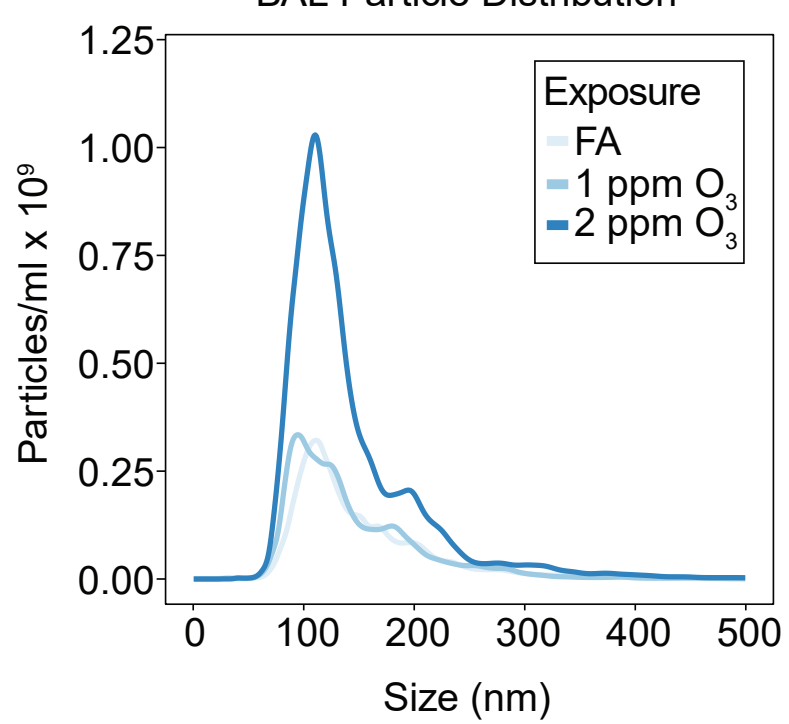

C

BAL Particle Size Mean

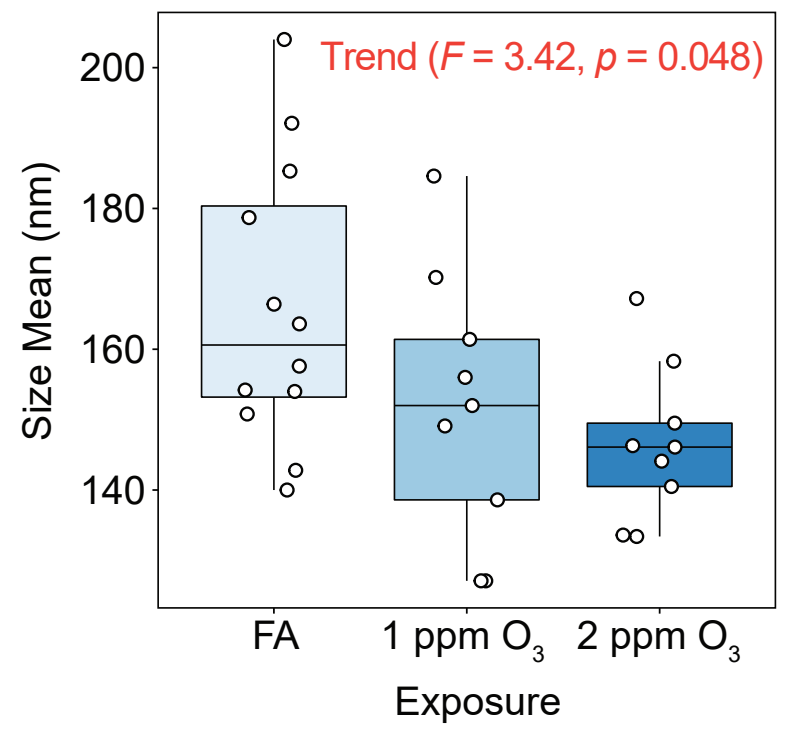

$\mathrm{B}$

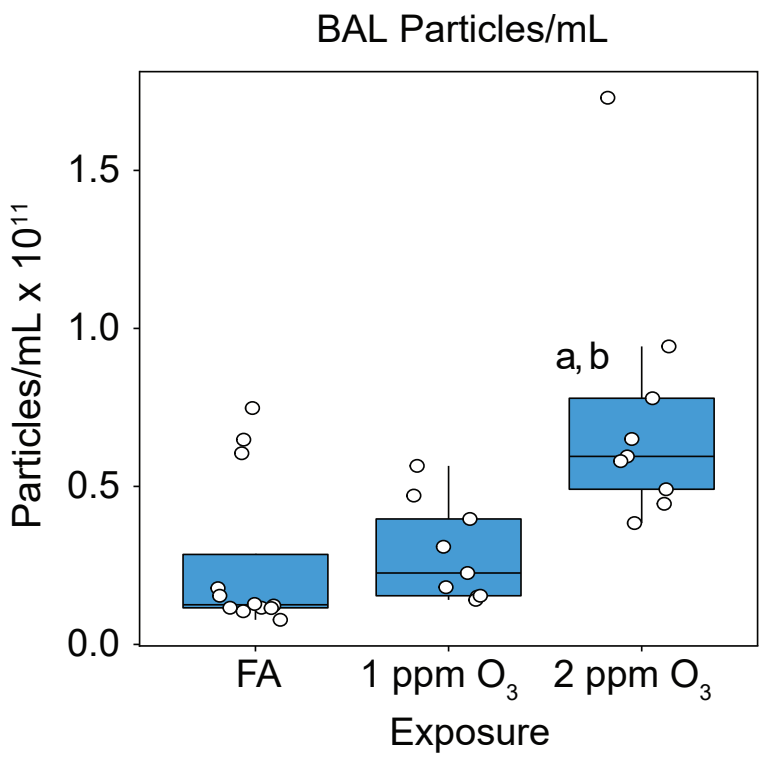

D

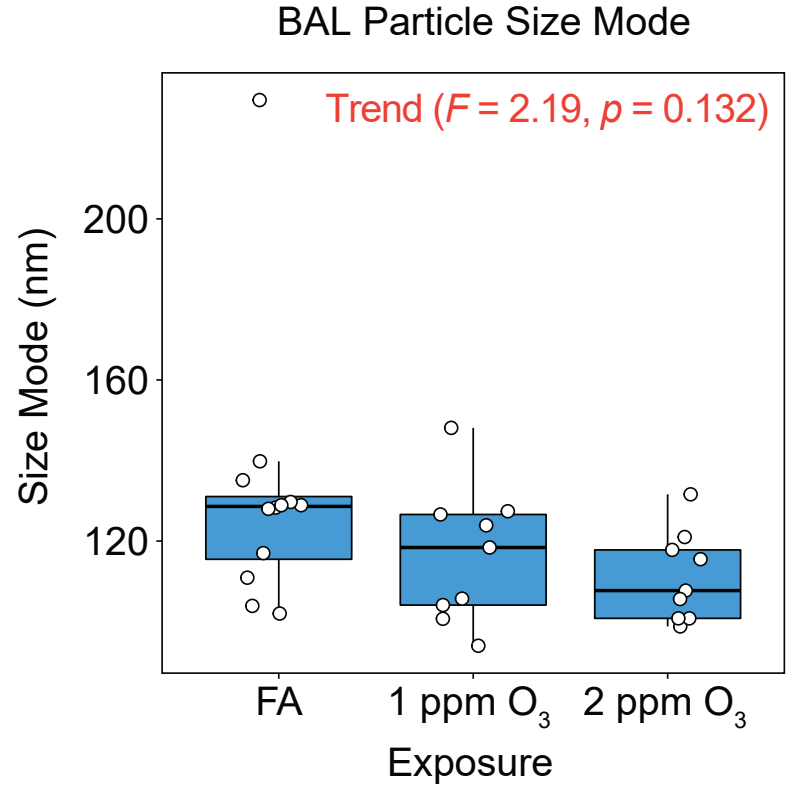



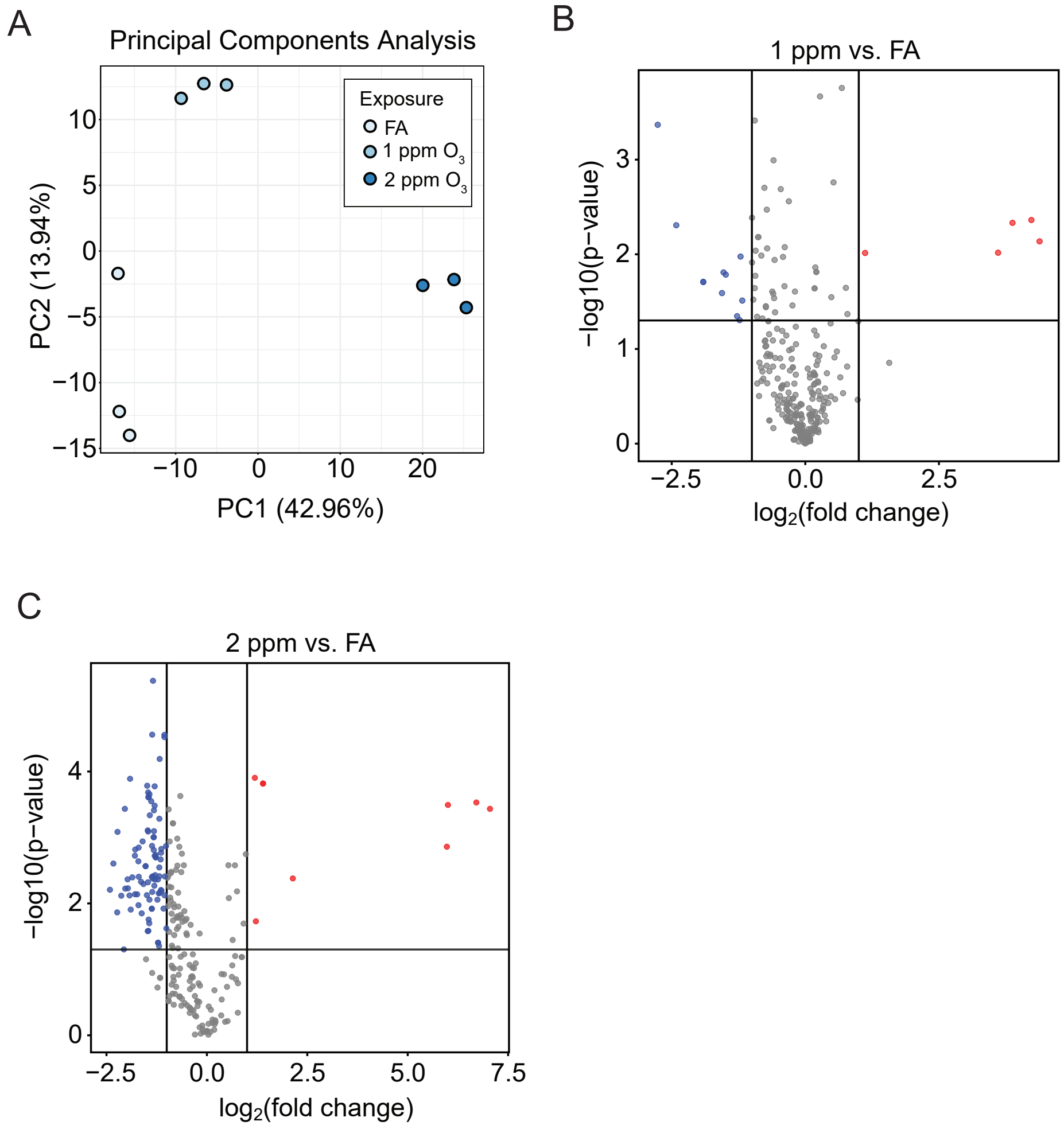
bioRxiv preprint doi: https://doi.org/10.1101/2020.06.17.157156; this version posted June 18, 2020. The copyright holder for this preprint (which was not certified by peer review) is the author/funder, who has granted bioRxiv a license to display the preprint in perpetuity. It is made Figure 3. available under aCC-BY-NC-ND 4.0 International license.

A

Top 50 Most Variable EV-miRNAs

Mean Centered

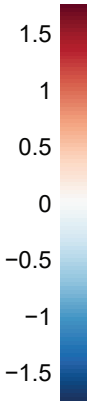

.

miR-23a-3p miR-222-3p $\mathrm{miR}-10 \mathrm{a}-5 \mathrm{p}$
$\mathrm{miR}-351-5 \mathrm{p}$ $m i R-351-5 p$
$m i R-125 a-5 p$ miR-125a-5p
miR-99a-5p miR-99a-5p
miR-652-3p $\mathrm{miR}-652-3 p$
$\mathrm{miR}-191-5 \mathrm{p}$ $m i R-191-5 p$
$m i R-200 a-3 p$ $m i R-200 a-3 p$
$m i R-30 e-5 p$ miR-27b-3p miR-26b-5p miR-30c-1-5p miR-30c-2-5p let-7a-1-5p let-7a-2-5p let-7c-2-5p let-7c-1-5p let-7d-3p miR-26a-2-5p miR-26a-1-5p miR-21-5p miR-30a-5p miR-99b-5p miR-30a-3p miR-23b-3p miR-30b-5p let-7e-5p let-7f-2-5p let-7f-1-5p let-7f-7b-5p
let $7 \mathrm{p}-5 \mathrm{p}$ let-7d-5p let-7g-5p let-7i-5p miR-200b-3p $\operatorname{miR}-200 c-3 p$ miR-146b-5p miR-1298-5p miR-378-3p miR-320-3p
miR-92b-3p miR-92b-3p $\mathrm{miR}-423-3 \mathrm{p}$
$\mathrm{miR}-423-5 \mathrm{p}$ $\mathrm{miR}-423-5 \mathrm{p}$
$\mathrm{miR}-2137+$ $\mathrm{miR}-2137++33$
$\mathrm{miR}-2137++$ $\mathrm{miR}-2137 \_+-2$
$\mathrm{miR}-2137$ miR-2137_+_ $\operatorname{miR}-22-3 p$ $\mathrm{miR}-24-1-3 \mathrm{p}$ miR-24-2-3p
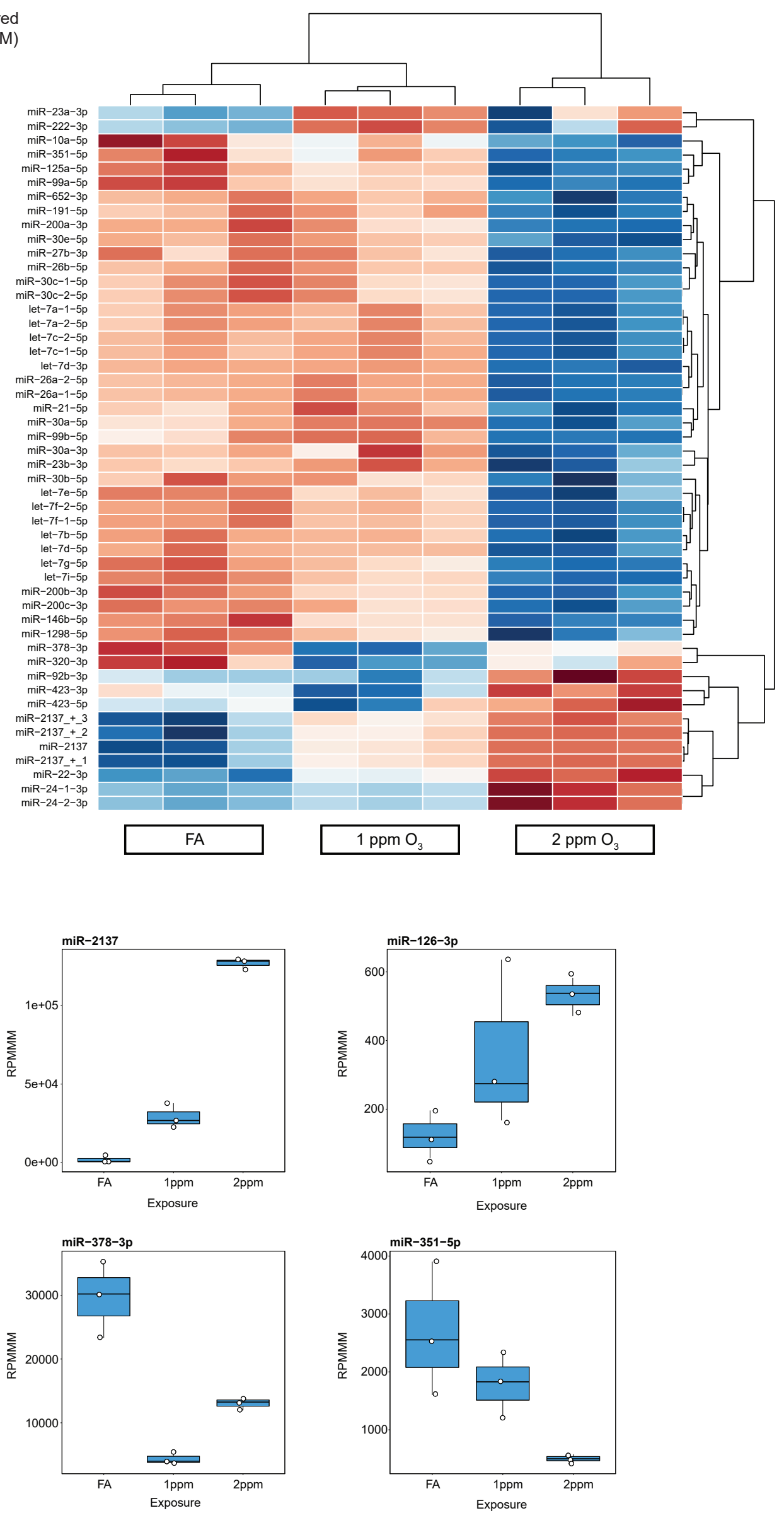
bioRxiv preprint doi: https://doi.org/10.1101/2020.06.17.157156; this version posted June 18, 2020. The copyright holder for this preprint (which was not certified by peer review) is the author/funder, who has granted bioRxiv a license to display the preprint in perpetuity. It is made

Figure 4.

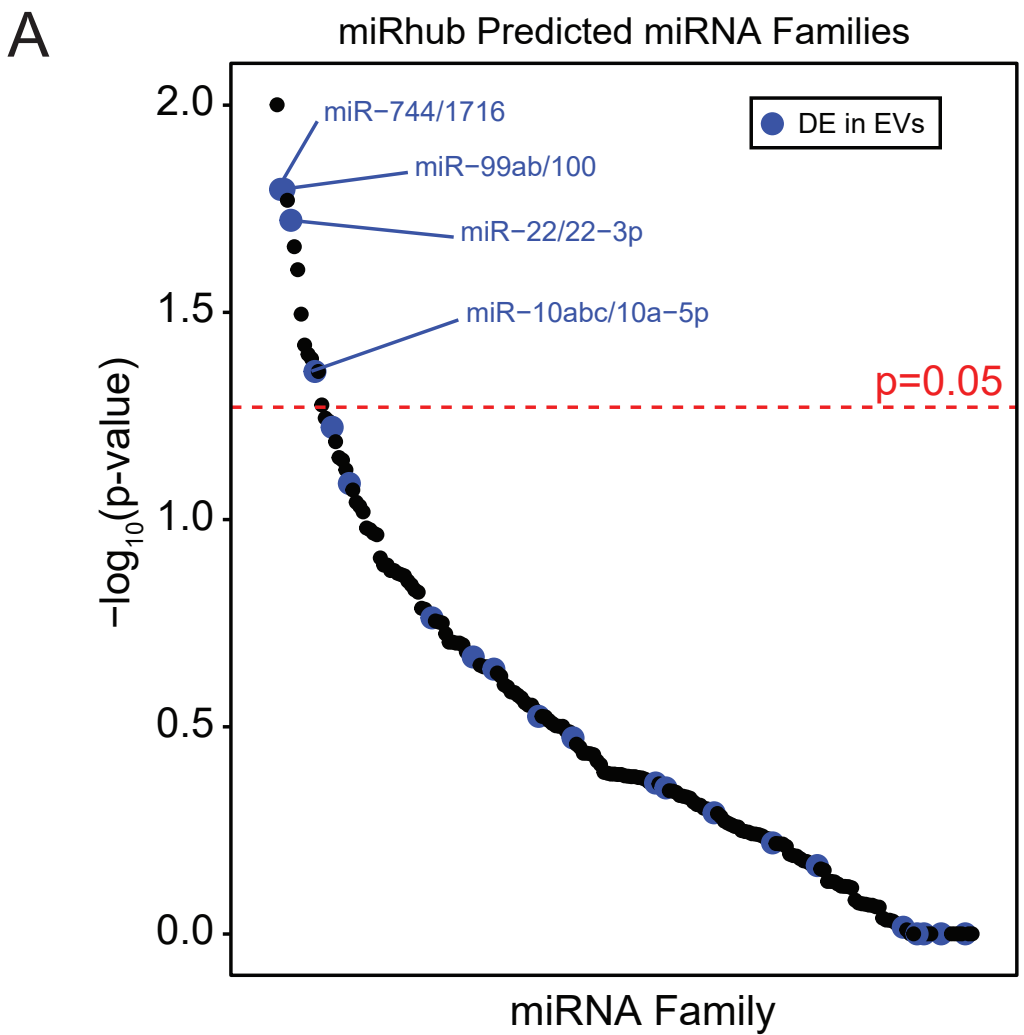

B

MiRNA

mRNA target
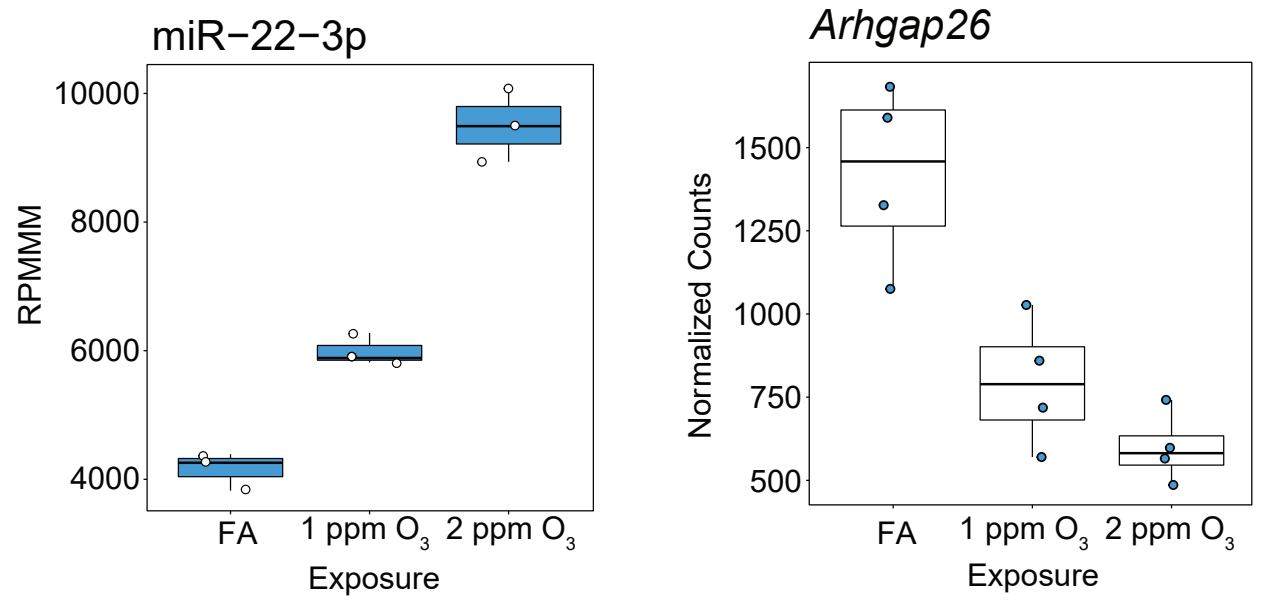